\title{
Severe coal tar sealcoat runoff toxicity to fish is prevented by bioretention filtration
}

Jenifer K. Mclntyre ${ }^{1}$, Richard C. Edmunds ${ }^{2}$, Bernadita F. Anulacion ${ }^{3}$, Jay W. Davis ${ }^{4}$, John P. Incardona ${ }^{3}$, John D. Stark ${ }^{1}$, and Nathaniel L. Scholz ${ }^{3}$

${ }^{1}$ Washington State University, Puyallup Research and Extension Center, 2606 W. Pioneer Ave., Puyallup, WA 98371

${ }^{2}$ National Research Council Associates Program, under contract to Northwest Fisheries Science Center, National Marine Fisheries Service, NOAA, 2725 Montlake Blvd. E., Seattle, WA 98112 USA

${ }^{3}$ Environmental and Fisheries Science Division, Northwest Fisheries Science Center, National Marine Fisheries Service, NOAA, 2725 Montlake Blvd. E., Seattle, WA 98112

${ }^{4}$ U.S. Fish and Wildlife Service, Washington Fish and Wildlife Office, 510 Desmond Dr. S.E., Lacey, WA 98503

\section{Supporting Information}

Table S1. Water chemistry data. Page S2-S3

Table S2. Juvenile coho fish lengths and weights. Page S4

Figure S1. Map of coal tar sealcoat and asphalt test plots. Page S5

Figure S2. MSDS for coal tar sealcoat product. Page S6-S8

Figure S3. Images of zebrafish embryos with cardiovascular abnormalities. Page S9

Figure S4. Distribution of PAHs by ring number for each event. Page S10

Figure S5. Zebrafish embryo survival in dilutions of Event 1 runoff. Page S11

Figure S6. Zebrafish embryo sublethal toxicity in dilutions of Event 1 runoff. Page S12

Video S1. Fish showing loss of equilibrium at $24 \mathrm{~h}$ exposure to Event 2 runoff

Video S2. Fish showing surface swimming and gaping at $96 \mathrm{~h}$ exposure to Event 3 runoff 
Table S1. Water chemistry for conditioning of bioretention columns, influent water (control), runoff from coal tar sealcoat events (unfiltered or filtered with bioretention), and runoff from adjacent asphalt-only surface.

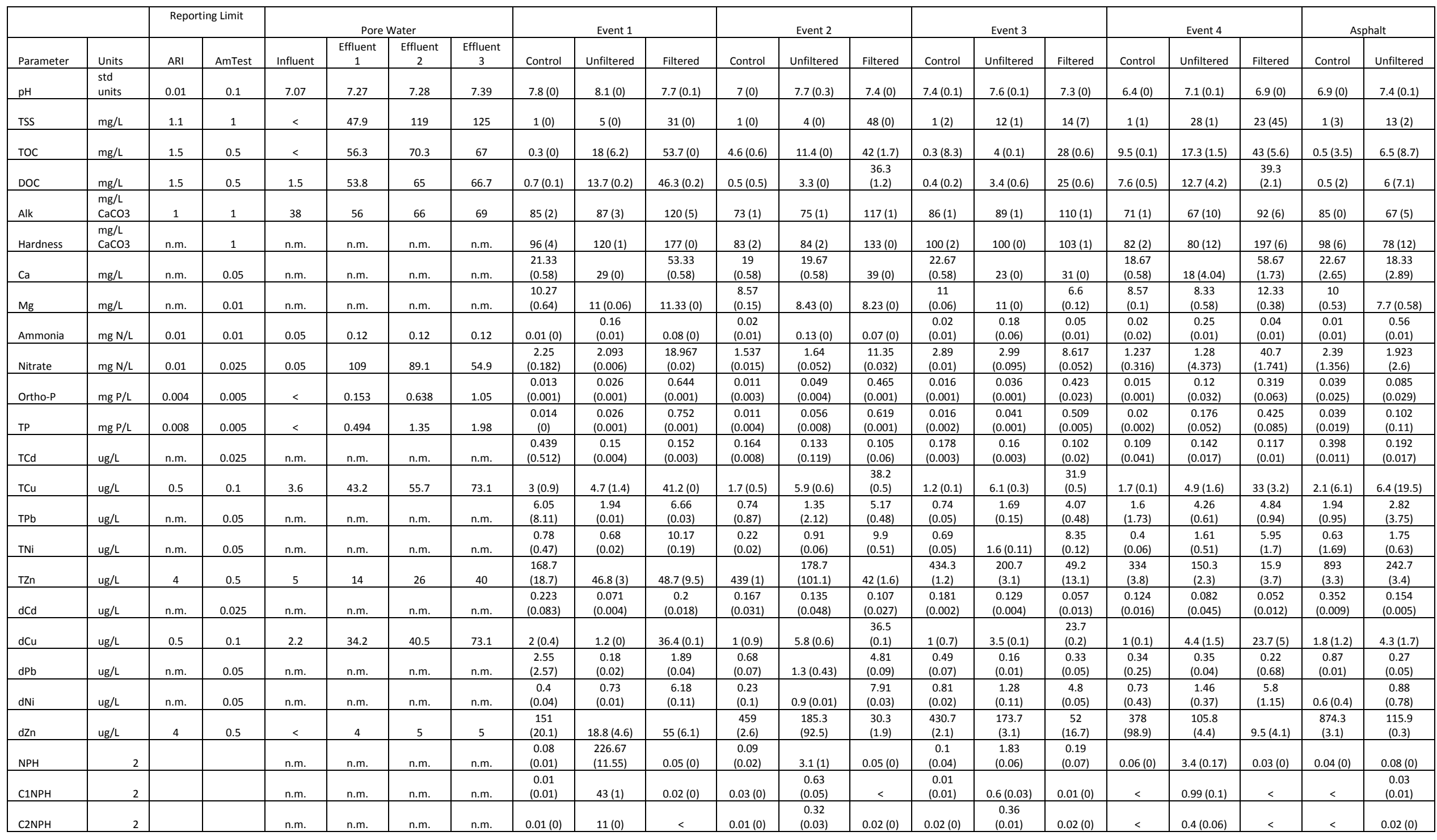




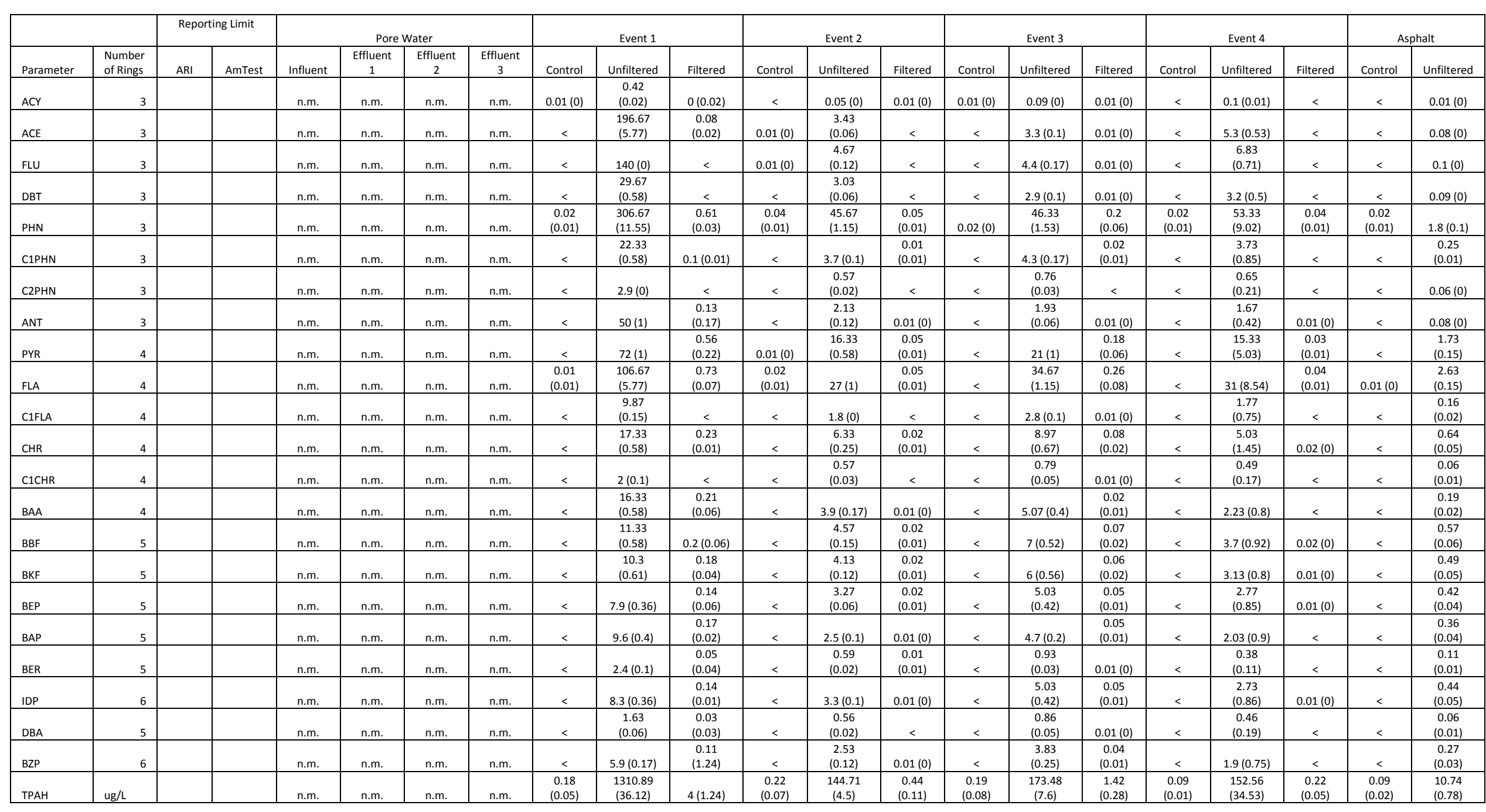

$\mathrm{NPH}=$ naphthalene, $\mathrm{ACY}=$ acenaphthylene, $\mathrm{FLU}=$ fluorine, $\mathrm{DBT}=$ dibenzothiophene, $\mathrm{PHN}=$ phenanthrene, $\mathrm{ANT}=$ anthracene, $\mathrm{PYR}=$ pyrene, $\mathrm{FLA}=$ fluoranthene, $\mathrm{CHR}=$ chrysene, $\mathrm{BAA}=$ benzo $[a]$ anthracene, $\mathrm{BBF}=$ benzo $[b]$ fluoranthene, $\mathrm{BEP}=\mathrm{perylene}, \mathrm{BAP}=$ benzo $[a]$ pyrene, $\mathrm{BER}=$ benzo[e]pyrene, IDP = indeno[1,2,3-cd]pyrene, DBA = dibenz $[a, h]$ anthracene $($ and $[a, c]), \mathrm{BZP}=\operatorname{benzo}[g h i]$ perylene, $\mathrm{Cx}=$ alkylated homologues. 
Table S2. Size of juvenile coho used in each runoff test.

\begin{tabular}{cccc}
\hline Event & Date & Length $^{\mathrm{a}}(\mathrm{mm})$ & Weight $(\mathrm{g})$ \\
\hline 1 & $9 / 19 / 2013$ & $68.6(8.9)^{\mathrm{b}}$ & $3.14(1.29)$ \\
2 & $9 / 26 / 2013$ & $66.5(8.6)$ & $3.28(1.29)$ \\
3 & $10 / 2 / 2013$ & $66.6(8.0)$ & $3.22(1.26)$ \\
4 & $4 / 14 / 2014$ & $55.5(5.5)$ & $1.79(0.58)$ \\
Asphalt & $9 / 2 / 2014$ & $74.8(7.4)$ & $4.43(1.39)$ \\
\hline
\end{tabular}

${ }^{\mathrm{a}}$ Total length

${ }^{\mathrm{b}}$ One standard deviation of the mean 


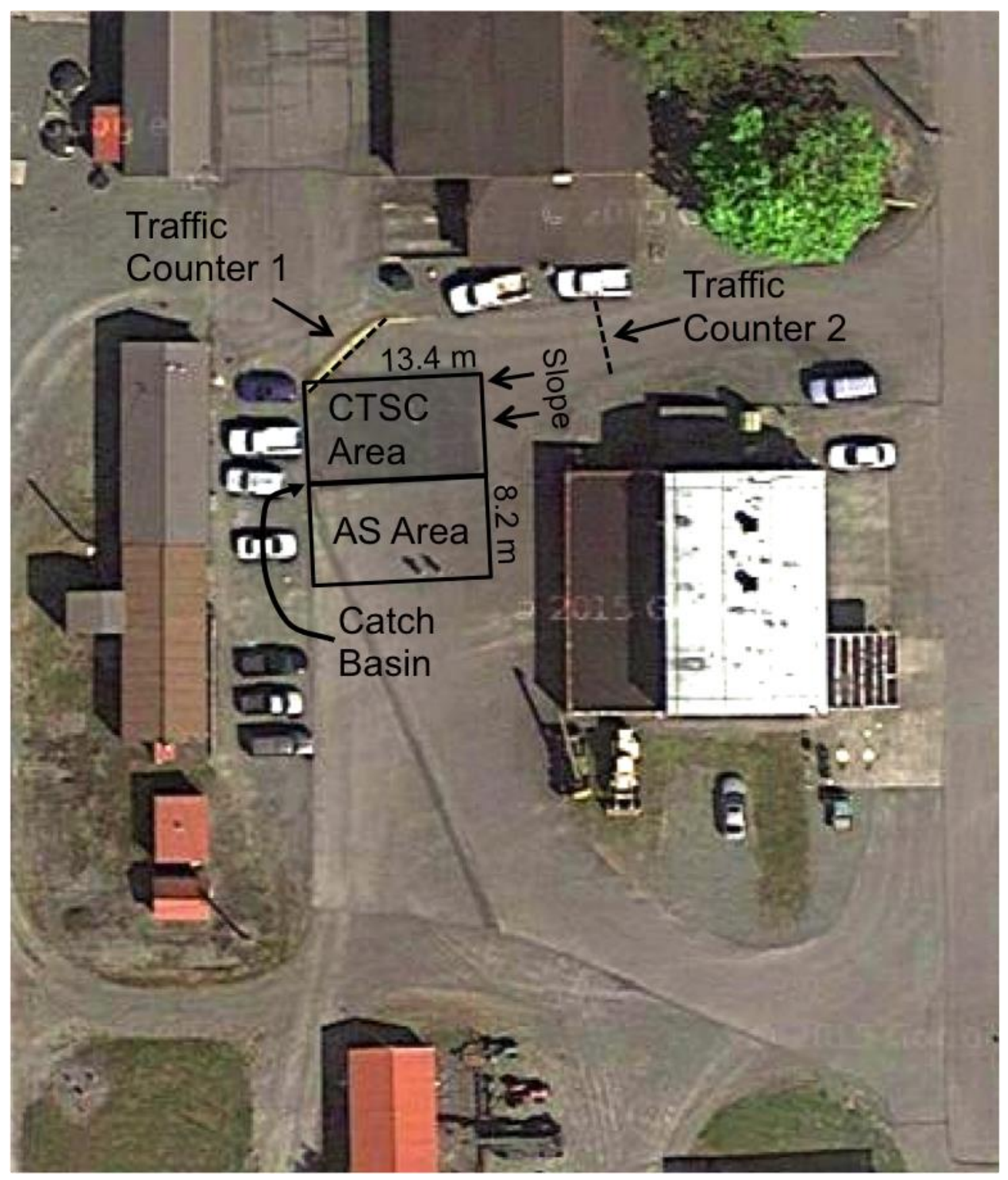

Figure S1. Aerial view of the coal tar sealcoat (CTSC) and asphalt-only (AS) plots at the WSU Puyallup Research \& Extension Center, showing the size of the plots and the location of the catch basin where runoff was collected during simulated rain events. Map data: Google. 
Figure S2. MSDS for coal tar sealcoat product

\author{
http://www.asphaltkingdom.com/sealer-technical-data.html \\ MATERIAL SAFETY DATA SHEET \\ In compliance with the Superfund Amendments and Reauthorizations Act (SARA Title III, section \\ 313), Federal Hazard Communications Regulations (WHMIS and OSHA CFR 1920:1200), and \\ with interest of informed use of our product, we are providing you with this Material Safety Data \\ Sheet. \\ In the events that you are not the person who needs this information, please direct this MSDS to \\ the person responsible for safe handling, disposal, and storage of products in your company. \\ All employees, agents, contractors, customers, or others who may handle this product should be \\ familiar with any warnings of precautionary procedures related to this product and to materials \\ made from it. \\ This MSDS will be updated regularly to reflect the most recent information in our possession. \\ Please ensure that obsolete MSDS sheets in your file of this product are discarded.
}

\author{
SECTION I - PRODUCT IDENTIFICATION \\ PRODUCT NAME:SealPave Driveway Sealer \\ MANUFACTURER NAME: SurfaceCoatingsCompany/International Marketing Distribution \\ EMERGENCY PHONE NUMBER: 866-399-5562 \\ AFTER 5 PM AND ON WEEKENDS: 866-399-5562 \\ ORIGINATOR: R.A.H. \\ TRADE NAMES \& SYNONYMS: Pavement Maintenance Coating \\ CHEMICAL FAMILY: N/A \\ EFFECTIVE DATE: $8 / 31 / 99$ \\ DATE SUPERSEDED: $5 / 1 / 05$
}

\title{
SECTION II - HAZARDOUS INGREDIENTS
}

Coal Tar Pitch

CAS \#65996-93-2

$\%$ by weight: $30-33 \%$

Listed in SARA Title III, Section 313: No

OSHA PEL: $0.2 \mathrm{mg} / \mathrm{m} 3$ (volatiles)

ACGIH TLV: $0.2 \mathrm{mg} / \mathrm{m} 3$ (volatiles)

STEL: N/A

LC50 : N/A

LD50: N/A

\section{Clay}

CAS \#1332-58-7

$\%$ by weight: $17-20 \%$

Listed in SARA Title III, Section 313: No

OSHA PEL: $5 \mathrm{mg} / \mathrm{m} 3$ (dust)

ACGIH TLV: $2 \mathrm{mg} / \mathrm{m} 3$ (dust)

STEL: $5 \mathrm{mg} / \mathrm{m} 3$ (dust)

LC50: N/A

LD50: N/A

Water

CAS \#7732-18-5

$\%$ by weight $45-50 \%$

Listed in SARA Title III, Section 313: No

OSHA PEL: N/A

ACGIH TLV: N/A

STEL: N/A

LC50: N/A 
LD50: CTI>320.000

$\mathrm{N} / \mathrm{A}=$ Not available or applicable

Ingredients total weight \% are below $100 \%$ only if all others unlisted are not considered

hazardous by any federal (OSHA, WHMIS, SARA), any state or province, or local Right-To-

Know regulations.

\section{SECTION III - PHYSICAL DATA}

APPEARANCE \& ODOR: Black or brownish black liquid with tar odor

BOILING POINT: $212^{\circ} \mathrm{F}$

VAPOR PRESSURE: $25 \mathrm{~mm} \mathrm{Hg}$

SPECIFIC GRAVITY: 1.0-1.3 PHYSICAL STATE: Liquid

SOLUBILITY IN WATER: Miscible FREEZING POINT: $32^{\circ} \mathrm{F}$

EVAPORATION RATE: 1 \% VOLATILE (by wt.): $50-53 \%$

PH: 6.5-8.0 THRESHOLD ODOR: N/A

WATER/OIL DIST. COEFFICIENT: $1 / 1$ VAPOR DENSITY: 1

SECTION 1V - FIRE AND EXPLOSION HAZARD DATA

FLAMABILITY CLASSIFICATION: Not regulated

FLASH POINT: N/A AUTO IGNITION TEMP: N/A

LOWER EXPLOSIVE LIMIT (LEL): N/A

UPPER EXPLOSIVE LIMIT (UEL): N/A

COMBUSTION PRODUCTS:

Hydrocarbon compounds, $\mathrm{CO} 2$ and $\mathrm{CO}$.

EXTINGUISHING MEDIA:

Foam/dry chemical/carbon dioxide

SPECIAL FIRE FIGHTING PROCEDURES:

Cool exposed containers to prevent steam pressure build up. Wear self-contained breathing equipment.

UNUSUAL FIRE AND EXPLOSION HAZARDS:

Containers may rupture due to steam pressure.

NFPA RATING: HEALTH: 2: FIRE 1: REACTIVITY: 0

UN/NA/PIN\#: N/A

IMPACT SENSITIVE: No

STATIC SENSITIVE: No

EXPLOSIVE POWER: N/A

BURNING RATE: N/A

\section{SECTION V - HEALTH HAZARD DATA}

THRESHOLDLIMIT VALUE: See Section II

ROUTES OF ENTRY: Skin, eyes, inhalation, ingestion.

EFFECTS OF OVEREXPOSURE:

Eyes: May cause eye irritation which in the absence of recommended first aid may result in severe burns.

Inhalation: May cause headaches and nausea. Prolonged and repeated inhalation may be harmful to respiratory system.

Skin: May cause irritation of skin or more harmful effects. When not washed off accentuated by sunlight, skin contact with the product volatiles may result in burns which may be severe.

Ingestion: May cause nausea, cramps, vomiting, diarrhea or acute effects. May be fatal in large amounts.

UNUSUAL CHRONIC TOXICITY:

May cause cancer of the skin, lungs, kidney, or bladder. Prolonged or repeated contact over many years in the absence of good hygiene and personal protection may lead to changes in skin pigmentation and skin tumors.

CARCINOGENIC:

Yes, listed in IARC, ACGIH, and NTP. WARNING: Using this product will expose you to a chemical known to the state of California to cause cancer.

EMERGENCY AND FIRST AID PROCEDURES: 
Eyes: Immediately flush with plenty of water for 15 minutes and call a physician.

Inhalation: If affected, remove to fresh air.

Skin: Wash thoroughly with plenty of water and soap.

Ingestion: Seek physician immediately, show MSDS or label, DO NOT induce vomiting.

\section{SECTION VI - REACTIVITY DATA}

STABILITY: Stable

CONDITIONS TO AVOID: Keep from freezing.

INCOMPATIBILTY (materials to avoid): Strong oxidizing agents.

HAZARDOUS POLYMERIZATION: Will not occur.

HAZARDOUS DECOMPOSITION PRODUCTS: N/A

CONDITIONS TO AVOID:N/A

SECTION VII - SPILL OR LEAK PROCEDURES

SARA TITLE III:

\# 302: No \# 304 CERCLA: No \#313: Yes RCRA: No

STEPS TO BE TAKEN IN CASE MATERIAL IS RELEASED OR SPILLED:

Ventilate the area. Wear suitable protective clothing, gloves \& eye/face protection. Contain and pick up waste materials. Put in a sealed approved container. Dispose of in accordance with federal, state and local regulations.

WASTE DISPOSAL METHOD: Dispose in accordance with Federal, State and Local

Regulations.

REPORTABLE QUANTITES (Ibs): N/A TPO (Ib): N/A

REGULATIONS: WHMIS, SARA, state and province HAZARDOUS WASTE:n/a

SECTION VIII - PRECAUTIONS FOR SAFE HANDLING AND USE

VENTILATION:

Local Exhaust: Required

RESPIRATORU PROTECTION:

Use only with adequate ventilation. If ventilation is inadequate, wear approved respiratory

equipment.

PROTECTIVE GLOVES: wear rubber gloves.

EYE PROTECTION: wear safety glasses, goggles, or face shield.

OTHER PROTECTIVE EQUIPMENT: wear suitable protective clothing.

ESTIMATED LD50. MG/KG: N/A

ESTIMATED LC50: N/A

SENSITIZATION: N/A

IRRITATION: Yes

\section{SECTION IX - REGULATORY INFORMATION}

Keep out of reach of children.

For professional and industrial use only.

Always read label plus precautions and follow directions carefully.

Keep from freezing.

Avoid contact with eyes, skin and clothing.

Wear suitable protective clothing, gloves and eye/face protection.

Wash thoroughly after using.

Do not breath vapor or spray mist.

Use only in well ventilated areas.

Keep containers closed when not in use.

DO NOT TAKE INTERNALLY.

Additional Technical Data Sheets and/or MSDS area available upon request.

THE INFORMATION AND RECOMMENDATIONS PROVIDED HEREIN ARE BELIEVED TO BE

ACCURATE AS OF THE DATA HEREOF. HOWEVER, SUCH INFORMATION AND

RECOMMENDATIONS ARE PROVIDED WITHOUT WARRANTY OF ANY KIND AND THIS

CORPORATION DISCLAIMS ANY AND ALL LIABILITY OR LEGAL RESPONSIBILITY FOR

USE OR RELIANCE UPON SAME. 

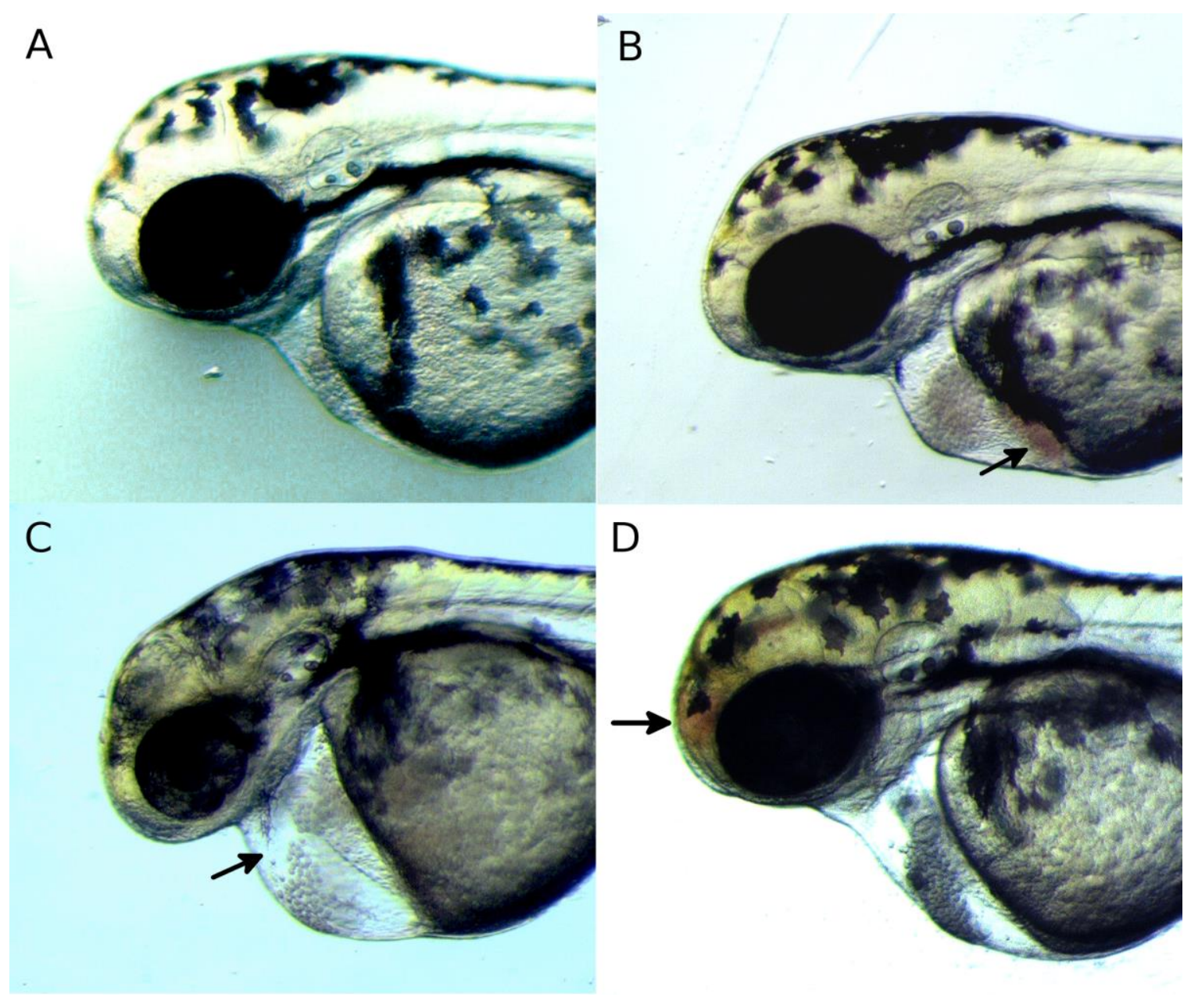

Figure S3. Representative examples of zebrafish embryos reared for $48 \mathrm{~h}$ in A) control water, or coal tar sealcoat runoff. Arrows show examples of common cardiovascular abnormalities: B) common cardinal vein pooling, C) severe pericardial edema, D) cranial hemorrhaging. 

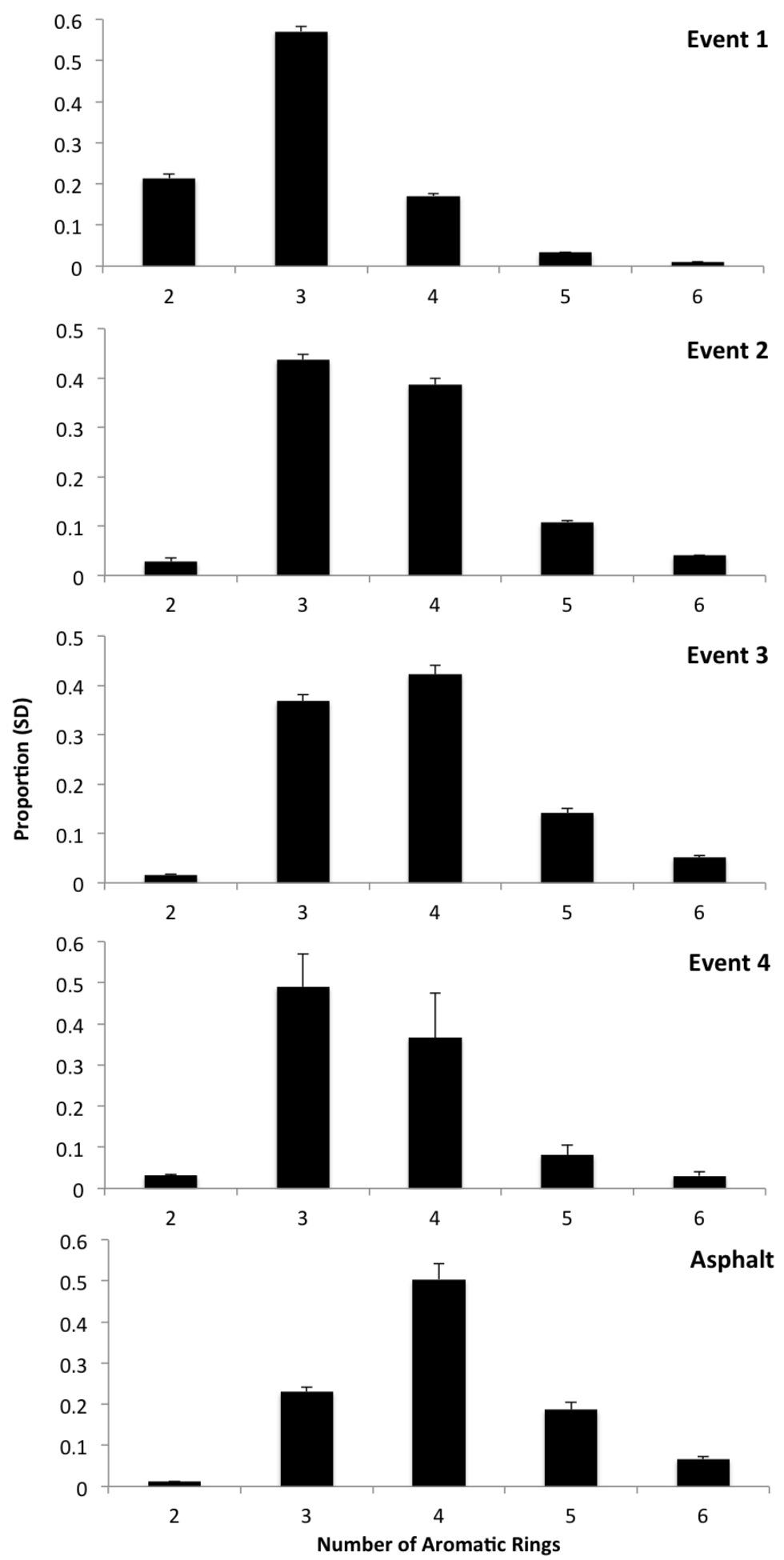

Figure S4. Distribution of PAHs by ring number in runoff from coal tar sealcoat for Events 1-4 plus runoff from the adjacent untreated asphalt plot. Error bars are \pm S.E.M. 


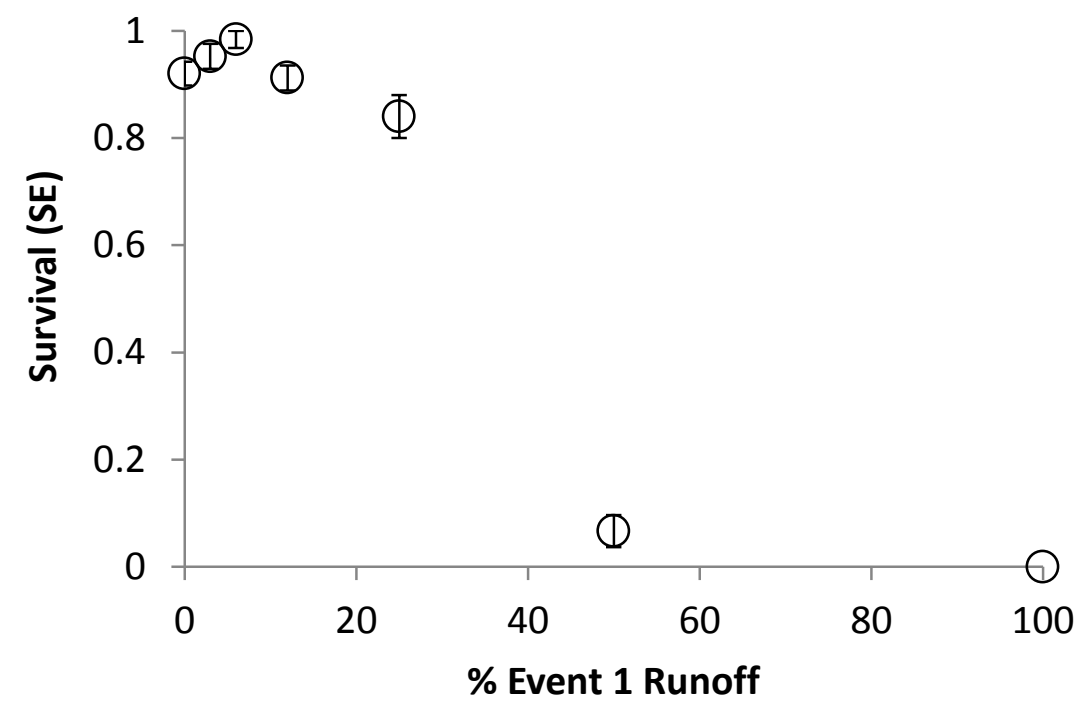

Figure S5. Survival of zebrafish embryos following $48 \mathrm{~h}$ exposure to dilutions of runoff from Event 1 . Mortality was significant only for $50 \%$ and $100 \%\left(\chi^{2}(25)=89.8, d f=25, p\right.$ $<0.001$, LC50 $=34 \%$ dilution). Error bars are \pm S.E.M. 

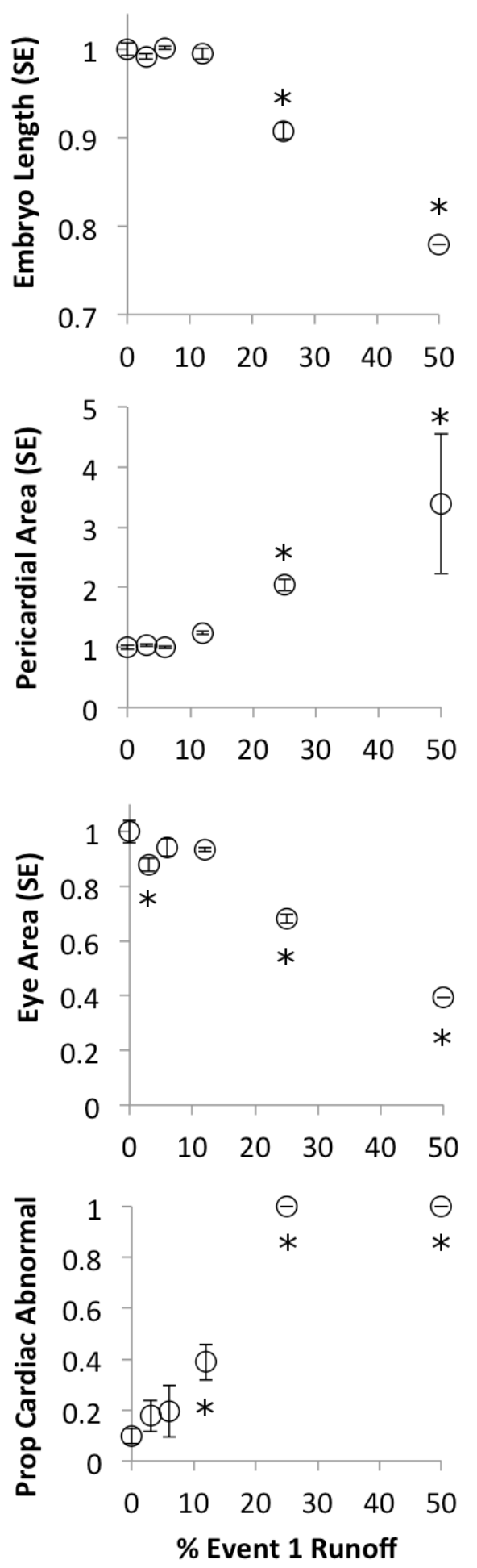

Figure S6. Morphometrics for zebrafish embryos exposed to dilutions of unfiltered runoff from Event 1. Values are relative to control means. Asterisks indicate significantly different from controls. Error bars are \pm S.E.M. 